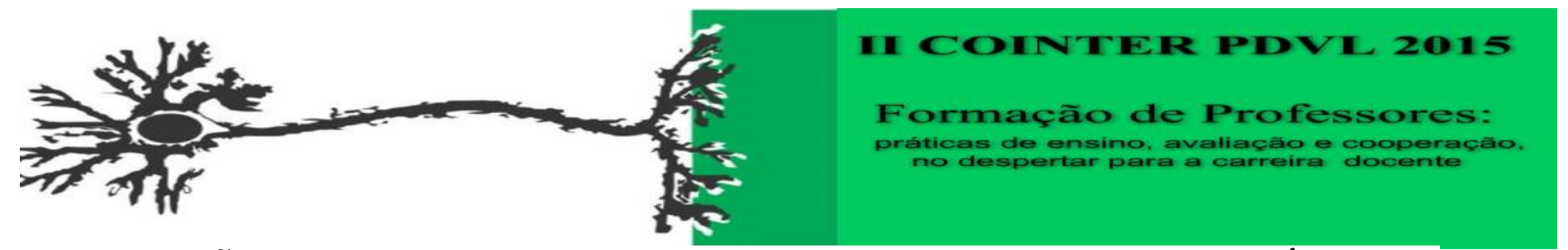

\title{
A GESTÃO dA ESCOLA A PARTIR DO PROJETO POLITICO PEDAGÓGICO E DO PLANO DE DESENVOLVIMENTO DA ESCOLAS EM ESCOLAS LOCALIZADAS NA ZONA DA MATA NORTE NOS ESTADO DE PERNAMBUCO
}

\author{
Apresentação: Comunicação Oral
}

\author{
Autor Principal ${ }^{1}$ Luiz Alberto Ribeiro Rodrigues; Coautor ${ }^{2}$ Adrianny Maria Barbosa de \\ Lima;
}

\begin{abstract}
Resumo
Esta pesquisa investigou dois instrumentos de planejamento escolar, o Projeto Político Pedagógico (PPP) e do Plano de Desenvolvimento da Escola (PDE). O objetivo foi discutir as concepções e práticas desses instrumentos em escolas públicas de Pernambuco e suas aproximações e/ou os distanciamentos entre as concepções existentes na literatura educacional.
\end{abstract}

$\mathrm{Na}$ literatura educacional, o PPP é conceituado como uma expressão da identidade pedagógica, instituída pelo princípio da autonomia e da participação da comunidade escolar. O PDE representa o planejamento estratégico da escola numa perspectiva empresarial, voltado a definir o melhor uso dos recursos que a escola recebe através de ações financiadas pelo MEC. Cada um representa uma diferente perspectiva política de gestão escolar, empresarial ou pedagógica.

O estudo seguiu a proposta de abordagem cognitiva de políticas públicas, fundamentado em que uma política deriva de um processo de interação, de relações de força que vão, dialeticamente, pouco a pouco se firmando. Utilizou-se como amostra, duas escolas estaduais da Zona da Mata Norte de Pernambuco, localizadas nos municípios de Carpina e Buenos Aires. Os dados foram coletados a partir dos documentos institucionais, PPP e PDE, e complementados por entrevistas semiestruturadas realizadas com técnicos da Gerência Regional de Educação, diretores, professores e educadores de apoio.

A prática observada nas escolas revelou que o planejamento sistematizado no PPP traduz uma tentativa de concepção política pedagógica da escola, que define objetivos formativos amplos. Por outro lado, foi observado que o PDE se configura como um planejamento financeiro/material vinculado a objetivos de melhoria da aprendizagem dos estudantes em áreas específicas na sala de aula. Como instrumento gerencial de planejamento, apresenta-se limitado a ações de natureza administrativas na escola, com objetivos de tornar mais eficiente o provimento de aprendizagem aos 'clientes'.

Esta pesquisa contribuiu para alimentar a linha de pesquisa em Política de Planejamento e gestão educacional e soma-se a estudos anteriores realizados nesta mesma região.

\section{Palavras-Chave: PPP, PDE, Gestão Escolar}

\footnotetext{
${ }^{1}$ Professor e Doutor em Educação, Upe, luiz.rodrigues@upe.br

${ }^{2}$ Ciências Biológicas, Upe, adriannyrosas_sarom@hotmail.com
} 


\section{Introdução}

Nas últimas duas décadas a gestão escolar no Brasil vem sendo afetadas por significativas ações da política nacional, que, com foco no gerenciamento e nos princípios de descentralização e responsabilização, ideologia presente na reforma do estado brasileiro em curso desde 1995.

No âmbito da escola tem se observado, entre as múltiplas atividades que integram o cotidiano da escola, a elaboração, execução de dois instrumentos de planejamento, o Projeto Político Pedagógico (PPP) e do Plano de Desenvolvimento da Escola (PDE). Tais projetos derivam de variadas concepções, intencionalidades e, ainda, dão distintos encaminhamentos à prática escolar. Assim, este estudo tem como objeto de investigação o Projeto Político Pedagógico e o Plano de Desenvolvimento da Escola em escolas da rede estadual de ensino de Pernambuco.

Esta pesquisa soma-se a estudos anteriores desenvolvidos na Região da Mata Norte e na Região Metropolitana do Recife, e contribui para alimentar a temática de investigação acerca das políticas de gestão e de planejamento da escola.

Como questões norteadoras, o Projeto está alicerçado nas seguintes indagações:

1) Como se configuram o Projeto Político Pedagógico e do Plano de Desenvolvimento da Escola em escolas públicas de Pernambuco?

2) Que importância é dada para a elaboração, execução e avaliação do Projeto Político Pedagógico e do Plano de Desenvolvimento da Escola em escolas públicas de Pernambuco?

3) Quais as aproximações e/ou os distanciamento entre as concepções e as práticas do Projeto Político-Pedagógico em escolas públicas de Pernambuco com as compreensões emancipadoras existentes na literatura educacional?

4) Quais as aproximações e/ou os distanciamento entre as concepções e as práticas do Plano de Desenvolvimento da Escola em escolas públicas de Pernambuco com as análises críticas existentes na literatura educacional?

\section{Fundamentação Teórica}

O Projeto Político Pedagógico constitui-se em expressão da própria a identidade da escola uma vez que, para Martins (1998, p. 71), “com seu projeto, o caminho escolhido tem a sua marca, a escola assume feição própria, adquire personalidade”. Para Cavagnari (1998, p. 99), o Projeto Político-Pedagógico é, também, o elemento balizador da autonomia administrativa, pedagógica, financeira e jurídica de uma unidade escolar de modo que ambos devem ser vistos como processos indissociáveis. 
O processo de construção do Projeto Político-Pedagógico sinaliza que foram dados passos em direção à conquista da autonomia escolar na medida em que traduz um assumir de responsabilidades por parte dos atores sociais que atuam na escola (VEIGA, 1998, p. 13).

A partir da análise feita por Marques (2000, p. 30), de que o Projeto PolíticoPedagógico pode possibilitar a continuidade das ações educativas desenvolvidas pela escola, resguardando-a da descontinuidade administrativa que tanto caracteriza a gestão pública brasileira, podemos apreender a existência de um potencial político-administrativo na elaboração e implementação do Projeto Político-Pedagógico, uma vez que, desta forma, a escola encontrará elementos que favoreçam a sua caminhada institucional e educacional.

$\mathrm{Na}$ construção e implementação do Projeto Político Pedagógico também está contemplada a dimensão de participação, pois a sua elaboração "é co-responsabilidade dos professores, dos pais, dos alunos, do pessoal técnico-administrativo e dos segmentos organizados da sociedade local, contando ainda, com a colaboração e a assessoria efetivas de profissionais ligados à educação" (VEIGA, 1998, 31).

Ao contrário, o processo de implementação do Projeto Político-Pedagógico requer que os atores sociais da escola exerçam um processo constante de reflexão e debates sobre o Projeto elaborado (o que já se constitui no desencadeamento da importante etapa avaliativa) para, sobretudo, ser explicitado os liames existentes entre o Projeto e as práticas educativas cotidianas.

Em 1998, no contexto do Estado e das políticas neoliberais que foram implementadas na década de 1990, ocorreu a implementação de uma política de gestão escolar para as regiões Norte, Nordeste e Centro-Oeste, sob o patrocínio do FUNDESCOLA, chamada de Plano de Desenvolvimento da Escola também conhecida como PDE escola. Em Pernambuco, a implantação do PDE ocorreu a partir do ano de 1999, inicialmente na Região Metropolitana do Recife e a partir de 2003 nas demais regiões. Depois de quase uma década, estudos como os desenvolvido por Rodrigues (2009), apontam que a sua implementação provoca uma resignificação de conceitos da política educacional, tais como o sentido dos processos participativos, a qualidade da educação e o papel do planejamento na escola. A prática desta política parece atropelar políticas que insistem em garantir o Projeto Político Pedagógico como instrumento fundamental para a gestão escolar.

O discurso que sustenta o PDE procura afirmar a necessidade do planejamento estratégico da escola, como uma metodologia necessária para a eficiência do acesso dos alunos ao processo de aprendizagem, produto principal da escola mediado por ações administrativas. 
Nesse sentido, Xavier e Amaral Sobrinho (1999) porta vozes de um discurso na defesa de um modelo de escola que, administrativamente, respondesse pela aprendizagem de seus alunos, afirmam: "Uma concepção de escola como organização que deve prover o ensino de qualidade aos clientes que demandam seus serviços e que, no ensino fundamental, tem direito constitucional a esses serviços" (ibidem, p. 7).

\section{Metodologia}

Assim sendo, nesta pesquisa seguiu-se o caminho metodológico conhecido como abordagem cognitiva das políticas públicas, defendida por MULLER \& SURE (2002). Tomase como ponto de partida a hipótese de que a ação pública no Estado moderno é resultante de um dinâmico processo de práticas sociais, em um determinado momento histórico, capaz de processar a construção social da realidade (ibidem). Uma política deriva de um processo de interação, de relações de força que vão, dialeticamente, pouco a pouco se firmando.

Procurou-se explicitar a política presente na gestão escolar a partir da relação de coerência que vai existindo entre diversos elementos de um programa, sobretudo no que se refere aos seus objetivos. É também fundamental observar que na especificidade de uma política está a questão da evolução do Estado em relação ao modo como se dão as relações entre os poderes públicos e privados. E por fim o modo como acontece o processo de regulação dos conflitos e a harmonização dos interesses. Assim expressam estes autores: a especificação de política pública pode ser assim agrupada em "um quadro normativo de ação; ela combina elementos de força pública e elementos de competência (espertise); ela tende a constituir uma ordem local" (ibidem. p. 14).

Assim sendo, na análise procurou-se identificar, descrever e analisar como ela foi instituída no âmbito das escolas, que traços de mudanças foram deixados nos textos e que sentidos políticos vão se afirmando, seja em favor do mercado, ou em favor de uma sociedade democrática.

Os dados foram coletados, inicialmente de fonte documental a partir da leitura e análise do Projeto Político Pedagógico e do Plano de Desenvolvimento da Escola, bem como de entrevistas semiestruturadas feitas com o diretor, coordenador de apoio e membros do Conselho Escolar (representante dos professores, funcionários, alunos e pais).

Também serão fontes de dados os documentos que originaram as ações relacionadas com o PPP e o PDE. Os dados obtidos foram interpretados à luz do referencial de análise de política pública (MULLER \& SURE 2002) combinada com a teoria de análise do discurso segundo Norman Fairclough. 


\section{Resultados e Discussão}

Inicialmente buscou informações sobre os programas em estudo na Gerência Regional de Educação, GRE Mata Norte.

A pesquisa foi realizada em duas escolas estaduais de regime semi-integral, localizada na Zona da Mata Norte de Pernambuco. A escola1 (perfil).

\begin{tabular}{|l|l|l|l|l|}
\hline $\begin{array}{l}\text { Municípios e } \\
\text { escolas }\end{array}$ & $\begin{array}{l}\text { IDEB dos } \\
\text { pesquisadas } \\
\text { (séries finais do } \\
\text { ensino } \\
\text { fundamental } \\
\text { Rede estadual) }\end{array}$ & $\begin{array}{l}\text { IDEB das } \\
\text { escolas } \\
\text { pesquisadas- } \\
2011\end{array}$ & $\begin{array}{l}\text { IDEB } \\
\text { Nacional } \\
\text { (Séries finais } \\
\text { do ensino } \\
\text { fundamental) }\end{array}$ & $\begin{array}{l}\text { Estadual } \\
\text { (séries finais } \\
\text { do do ensino } \\
\text { fundamental) }\end{array}$ \\
\hline $\begin{array}{l}\text { Bueno Aires } \\
\text { escola 1 }\end{array}$ & 2,9 & 2,8 & 4,1 & 3,3 \\
\hline $\begin{array}{l}\text { Carpina } \\
\text { escola 2 }\end{array}$ & 3,4 & 3,6 & 4,1 & 3,3 \\
\hline
\end{tabular}

(INEP, 2013)

A escola pesquisada no município de Buenos Aires, Escola1, está com o IDEB 2,8, índice um pouco abaixo da média do município e abaixo em $16 \%$ menor que média estadual. A escola pesquisada no município de Carpina, Escola2, está com o IDEB 3,6, índice um pouco maior que a média do município e maior do que a média estadual que é de 3,3.

Pode observar que o IDEB do Estado de Pernambuco diminuiu, passando de 3,4 em 2010 para 3,3 em 2013.

A escola1 tem 682 alunos matriculados, das quais 410 no fundamental, 160 no médio, 62 no EJA médio e 50 EJA fundamental... A escola2 tem 1401 alunos matriculados, das quais 256 estão no fundamental regular, 472 no ensino regular, 264 no médio semi integral e 312 no EJA. 
Mapa de Entrevistas

\begin{tabular}{|l|l|l|}
\hline $\begin{array}{l}\text { Identificação do } \\
\text { entrevistado }\end{array}$ & Instituição & Função \\
\hline Técnica educacional & GRE Mata Norte & Técnica em normatização \\
\hline Supervisora & GRE Mata Norte & $\begin{array}{l}\text { Supervisora de Tecnologia da } \\
\text { Informação }\end{array}$ \\
\hline Diretor1 & Escola1 & Diretor escolar \\
\hline Educadora1 & Escola1 & Educadora de apoio \\
\hline Professor1 & Escola1 & Professor \\
\hline Professor2 & Escola1 & Professor \\
\hline Diretor 2 & Escola 2 & Diretor escolar \\
\hline Educadora2 & Escola 2 & Educadora de apoio \\
\hline Professora 3 & Escola 2 & Professor \\
\hline Professor 4 & Escola 2 & Professor \\
\hline
\end{tabular}

a) Quanto as configurações que o Projeto Político Pedagógico e o Plano de Desenvolvimento da Escola apresentam nas escolas públicas.

Conforme dados obtidos por meio de entrevistas, o PPP da escola "é onde estão todos os objetivos que a escola quer cumprir por um determinado tempo, no geral por dois anos. [...] Além disso, ele é um documento necessário para o credenciamento das instituições escolares". (técnica educacional). No âmbito da escola o PPP é compreendido como "a identidade da escola construída democraticamente. [...] Nele está a concepção de qualidade da educação e a política de responsabilidade e de compromisso do professor.” (diretor1). Outro aspecto referido ao PPP é sua vinculação ao Plano de Desenvolvimento da Escola PDE. “O PPP estar atrelado ao PDE da escola, porque se não tiver o PPP não tem acesso ao PDE na escola". (Educadora1).

Na sua concepção o PDE é uma política originária do MEC, "para subsidiar as escolas no que diz respeito a recursos pedagógicos focando somente os alunos, para que possam 
adquirir recursos para melhorar as aulas [...], para uma melhor aprendizagem". (Supervisora). É um plano de desenvolvimento com diversos projetos, "que vai dar subsídios financeiros para comprar materiais para pagar capacitação para professores. [...] ele tem objetivo de sanar aqueles problemas que são determinados pelos próprios professores”.(técnica educacional).

A implementação do PDE na GRE Mata Norte vem desde 2003. Seus objetivos estão voltados para resolver necessidades materiais para a sala. Em sua metodologia ele "reune os professores para cada um na sua área dizer qual a necessidade e justamente o gestor vai colocar isso no plano de ação, que é justamente aí que iremos distribuir os recursos e os objetivos". (Supervisora). Nas escolas pesquisadas o PDE foi iniciado em 2007, seguindo orientações da GRE Mata Norte.(educadora1). Para os educadores o objetivo do PDE na escola é "acompanhar o desenvolvimento do ensino para uma melhoria da qualidade do ensino." (educador1). Também está ligado aos sistemas de avaliação da educação básicas, tais como o IDEB e ao IDEP, “com vistas a criar condições para alcançar a meta estabelecida pelo governo do Estado e governo federal". (idem).

Em cada escola o PDE foca na aprendizagem do aluno, na diminuição da evasão e da reprovação escolar. (supervisora). Esse plano "vai dar subsídios financeiros para comprar materiais, pagar capacitações para professores". (técnica educacional).

Uma leitura mais abrangente acerca dos fins do PDE foi percebido na escola1, "fazer com que a escola se desenvolva e venha garantir para a sociedade, para os alunos e para a família o direito de aprender e o direito de progredir na vida" (diretor1). Essa concepção é acompanhada por uma educadora de apoio entrevistada, "o PDE é realizado para acompanhar o desenvolvimento do ensino para uma melhoria da qualidade do ensino quando é elaborado em um contexto com o PPP da escola".(educadora1).

\section{b) Quanto a importância dada para a elaboração execução e avaliação do PPP e o} PDE.

A importância atribuída ao PDE pela escola, está vinculada a possibilidade de que ele seja traduzido em recursos para a escola.

"Participam da elaboração do PDE, professores e funcionários. As articulações criadas pelo PDE e os recursos que vem para a escola tem contribuído muito para a construção da aprendizagem" (diretor 2)

"O conselho escolar vai participar não somente da questão da verba, mas do ensino, da aprendizagem" (diretor1) 
Também foi possível entender que as decisões sobre questões financeiras, ao contrario do que defende a política do PDE, não é objeto de discussão entre os membros do conselho escola. A participação nas decisões sobre o PDE é algo limitado aos gestores.

"Não sei lhe dar esta garantida, por que a outra gestora era que resolvia sobre a questão do PDE. Quando vinha para o grupo já era assim com ações definidas em que já ia resolver com o PDE e pronto".(educadora1)

"Pelo que eu saiba tem algumas reuniões com a direção e com a coordenação para saber o que vai ser colocado". (professor1)

c) Analisar as aproximações e/ou os distanciamentos entre as concepções e as práticas do Projeto Político-Pedagógico nas escolas públicas de Pernambuco com as compreensões emancipatórias existentes na literatura educacional;

Realizar um trabalho voltado para a realidade da escola, buscando desenvolver competências e habilidades no trabalho pedagógico por meio de gestão democrática. (escola1)

Movimentar ações de forma organizada mediante prospectiva que articule práticas convenientes á qualificação do processo educacional presente, á visão do futuro dos que demandam á unidade escolar. (escola2)

d) Analisar as aproximações e/ou os distanciamentos entre as concepções e as práticas do Plano de Desenvolvimento da Escola nas escolas públicas de Pernambuco com as análises críticas existentes na literatura educacional

Para os interesses dessa pesquisa foi considerado as fontes documentais de dados para análise, os documentos solicitados as escolas o Projeto Politico Pedagógico (PPP), O Plano de Desenvolvimento da Escola (PDE). As duas escolas disponibilizaram os dois documentos.

Foram apresentados as escolas os objetivos desse projeto aos Gestores das escolas selecionadas e solicitado o consentimento para a realização das entrevistas. As informações coletadas nessa pesquisa, seguiu os princípios éticos em pesquisa social. 
O estudo seguiu a proposta de abordagem cognitiva de políticas públicas, Utilizou-se como amostra os dados coletados a partir dos documentos institucionais, PPP e PDE, e complementados por entrevistas semi-estruturadas com os diretores, educadores de apoio e professores que participaram da participaram da elaboração do Projeto Politico Pedagógico (PPP) e do Plano de Desenvolvimento da Escola (PDE) das escolas onde foram feitas as pesquisas. Esta pesquisa contribuiu para alimentar a linha de pesquisa em Política de Planejamento e gestão educacional e soma-se a estudos anteriores realizados nesta mesma região.

\begin{tabular}{|l|}
\hline \multicolumn{1}{|c|}{ Cronograma } \\
\hline Resumo das atividades: \\
\hline 1 - Participação nos encontros do Grupo de Estudos sobre Pesquisa e/ou nos encontros de \\
acompanhamento da Pesquisa (Professor-Orientador e alunos-pesquisadores) \\
\hline 2 - Contatos iniciais com as escolas \\
\hline 3 - Estudos de embasamento sobre a área da gestão escolar e dos temas específicos deste \\
Projeto (PPP e PDE) \\
\hline 4 - Participação em eventos sobre temáticas relacionadas à área da gestão escolar e/ou com a \\
especificidade da temática deste Sub-Projeto \\
\hline 5 - Participação em eventos relacionados com a produção cientifica... \\
\hline 6 - Atividades de observação nas escolas \\
\hline 7 - Leitura dos PPP e dos PDE \\
\hline 8 - Avaliação do comitê de ética \\
\hline 9 - Realização das entrevistas \\
\hline 10 - Sistematização dos dados coletados \\
\hline 11 - Análise dos dados \\
\hline 12 - Elaboração e entrega de relatórios (parciais e conclusivo) \\
\hline
\end{tabular}




\begin{tabular}{|c|c|c|c|c|c|c|c|c|c|c|c|}
\hline \multicolumn{12}{|c|}{ Cronograma de Execução: } \\
\hline & \multicolumn{11}{|c|}{ M ES ES } \\
\hline & MAI & JUN & JUL & AGOS & SET & OUT & NOV & DEZ & JAN & FEV & MAR \\
\hline 1 & $\mathbf{X}$ & $\mathbf{X}$ & & & $\mathbf{X}$ & $X$ & & & & & \\
\hline 2 & & & & $\mathbf{X}$ & $\mathbf{X}$ & & & & & & \\
\hline 3 & & $\mathbf{X}$ & $\mathbf{X}$ & $\mathbf{X}$ & $\mathbf{X}$ & & & & & & \\
\hline 4 & & $\mathbf{X}$ & & $\mathbf{X}$ & $\mathbf{X}$ & $\mathbf{X}$ & & & & & \\
\hline 5 & & & & $\mathbf{X}$ & $\mathbf{X}$ & $\mathbf{X}$ & & & & & \\
\hline 6 & & & & & $\mathbf{X}$ & $\mathbf{X}$ & $\mathbf{X}$ & $\mathbf{X}$ & & & \\
\hline 7 & & & & & & $\mathbf{X}$ & $\mathbf{X}$ & & & & \\
\hline 8 & $\mathbf{X}$ & & & & & & & & & & \\
\hline 9 & & & & & & $\mathbf{X}$ & $\mathbf{X}$ & $\mathbf{X}$ & & & \\
\hline 10 & & & & & & & & $\mathbf{X}$ & $\mathbf{X}$ & $\mathbf{X}$ & \\
\hline 11 & & & & & & & & $\mathbf{X}$ & $\mathbf{X}$ & $\mathbf{X}$ & \\
\hline 12 & & & & & & & & & & $\mathbf{X}$ & $X$ \\
\hline
\end{tabular}

\section{Conclusões}

Esta pesquisa contribuiu para alimentar a linha de pesquisa em Política de Planejamento e gestão educacional e soma-se a estudos anteriores realizados nesta mesma região.

A prática observada nas escolas revelou que o planejamento sistematizado no PPP traduz uma tentativa de concepção política pedagógica da escola, que define objetivos formativos amplos. Por outro lado, foi observado que o Plano de Desenvolvimento se configura como um planejamento financeiro/material vinculado a objetivos de melhoria da aprendizagem dos estudantes em áreas específicas na sala de aula. Como instrumento gerencial de planejamento, apresenta-se limitado a ações de natureza administrativas na escola, com objetivos de tornar mais eficiente o provimento de aprendizagem aos 'clientes'. 


\section{Referências}

AMARAL SOBRINHO, J. O plano de Desenvolvimento da Escola e a gestão escolar no Brasil: Situação atual e perspectiva. Documento preliminar. Março de 2001. Disponível em: www.inep.gov.br/pesquisa/bbe-online/det.asp?cod=508158\&type=r. Acesso em: 21 maio 2007.

CAVAGNARI, L. B. Projeto Político-pedagógico, autonomia e realidade escolar: entraves e contribuições in: VEIGA, I. A. \& RESENDE, L. M. G. (orgs.).Escola: espaço do projeto político-pedagógico. São Paulo: Papirus, 1998. p. 95 - 112.

MARQUES, L. R. Projeto político-pedagógico: construindo a autonomia das escolas públicas? - As representações sociais dos conselhos. Dissertação de Mestrado. Centro de Educação/Mestrado em Educação da UFPE. Recife, 2000.

MARTINS, R. B. Educação para a cidadania: o projeto político-pedagógico como elemento articulador. In VEIGA, I. P. A.; RESENDE, L. M. G.(orgs).Escola: espaço do projeto politico-pedagógico. Campinas/SP: Papirus, 1998. p. 49 - 86.

MULLER, Pierre \& SUREL, Yves. A análise das políticas públicas. Tradução de Agemir Bavaresco e Alceu Ferraro. Pelotas: Educar, 2002.

RODRIGUES, L. A. R. Políticas de gestão escolar e a melhoria da qualidade do ensino uma análise do plano de desenvolvimento da escola na região da Mata Norte de Pernambuco (1999- 2007). Tese de Doutorado - Educação. UFPE, Recife, 2009.

RODRIGUES, L. A. R.; XIMENES, C. D. Percursos do Projeto Político Pedagógico e do Plano de desenvolvimento da escola em escolas estaduais localizadas na região metropolitana do Recife. In: Revista Formação. UPE, 2011. ISSN 1679-5466. Ano VI. V. 01. 